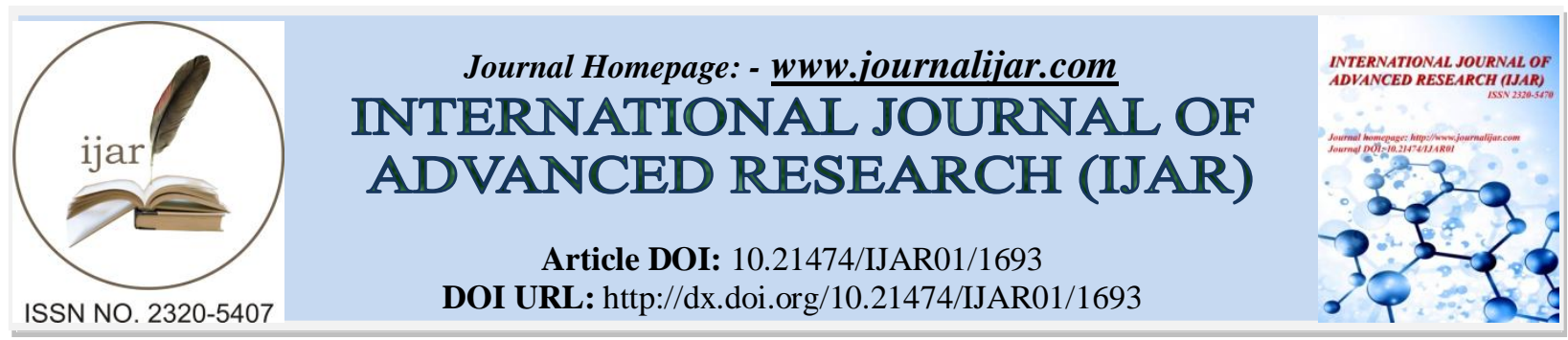

RESEARCH ARTICLE

\title{
ANALYSIS OF STOCK RETURN VOLATILITIES USING CLASSICAL AND BAYESIAN STOCHASTIC VOLATILITY MODELS IN DEVELOPED AND EMERGING MARKETS.
}

Selahattin Guris and Irem Sacakli Sacildi* .

Department of Econometrics, Marmara University, Istanbul, Turkey.

\section{Manuscript Info}

Manuscript History

Received: 12 July 2016

Final Accepted: 16 August 2016

Published: September 2016

Key words:-

Volatility, Bayesian Stochastic Volatility

Models, Efficient Method of Moments,

Markov Chain Monte Carlo.

\section{Abstract}

The aim of this study is to estimate and compare the classical and Bayesian stochastic volatility models for stock returns of developed and developing 10 countries. For the reason that financial series have fat-tails in the conditional distribution Bayesian stochastic volatility models with fat-tailed residuals in the mean equation, asymmetric Bayesian stochastic volatility models that allow leverage effect via correlation between the volatility and mean equation residual and Bayesian stochastic volatility models that allow both leverage effect and fat-tailed residuals are also estimated. In general when examining the results of the models it is seen that Bayesian models give better results for all indexes.

Copyright, IJAR, 2016,. All rights reserved.

\section{Introduction:-}

Volatility represents the variability in the random component of the time series and measured by the standard deviation or variance of the returns. Volatility is a statistical measure that expresses the dispersion of time series and symbolize uncertainty in financial decision making by indicating the size and speed of the fluctuations in time series (Rachev et al. 2008). The returns of stock exchanges are different according to the development level of the countries. These differences also affect the return volatilities. Stock return volatility represents the variability of stock price changes during a period of time. Return volatilities can be explained by using ARCH/GARCH type models or classical stochastic volatility (SV) models, known as the volatility models.

Returns are heteroscedastic and the fluctuations of financial asset returns can have drift. Volatility clustering is called as drift and it explains the tendency of returns being in the low and high volatility periods. Mandelbrot (1963) was one of the first to put forward an idea that large changes in asset prices tend to be followed by large changes and small changes tend to be followed by small changes. Volatility clustering define the tendency between low and high volatility periods. Engle (1982) was the first that used Autoregressive Conditional Heteroscedasticity (ARCH) model to express volatility persistence. Conditional variance of returns at time $t$, is a linear function of the past squared observations. Being autoregressive means volatility tend to be persistent, being conditional expresses that volatility varies in time and heteroscedasticity states that volatility is not constant. Bollerslev (1986) generalized the model of Engle (1982) and suggested GARCH model to formulate the conditional variance as a linear function of past squared observations and past squared conditional variances. ARCH models assume that all relevant information is observed and the model correctly specified, the volatility is known or predetermined as of time (t-1), stochastic volatility (SV) or stochastic variance models assume that only some parts of these informations can be known, the real volatility is never observed and it is a latent variable (Andersen et al. 2005). SV models include an unobserved shock component occurred in the return variance in the characterisation of volatility dynamics. 
There are two approaches in stochastic volatility modeling. Even both of these approaches can be adaptable to one another, one of those is implemented in discrete time and the other one is implemented in continuous time. First one is the mixture of distributions hypothesis suggested by Clark (1973) where returns are directed by the time process according to the intensity of the news relevant to the prices. Second approach is based on Black and Scholes (1973) in which price and volatility process are modeled separately with continuous sample path diffusions directed by the stochastic differential equations. In practice continuous time models are generally converged to discrete time models. SV models are natural discrete time adaptation of continuous time models in modern finance theory. Hull and White (1987) introduced the continuous-time stochastic volatility models and the discrete-time SV models introduced by Taylor (1986).

There are alternative SV models in literature. While Stein and Stein (1991), Johnson and Shanno (1987) assume that $\sigma(t)$ follows an Ornstein-Uhlenbeck (OU) process with Brown motion, Hull and White (1987), Heston (1993) assume that it follows geometric Brown Motion. In the case of discrete time, many SV models can be seen as generalized GARCH models. There is not any specific method for choosing the appropriate functional form among SV models but determination of the correct SV function become important since marginal distribution of volatility is related to the functional form of stochastic volatility. Logarithmic SV model has been estimated by many methods: simple method of moments (MM) by Taylor (1986), generalized method of moments (GMM) by Melino and Turnbull (1990), simulated method of moments (SMM) by Duffie and Singleton (1993), quasi-maximum likelihood method (QML) by Harvey et al. (1994), efficient method of moments (EMM) by Gallant and Tauchen (1996). To provide maximum likelihood efficiency the auxiliary model has to take part in structural model. Gallant and Nycka (1987) used semi-nonparametric density for providing this efficiency. Gallant and Long (1997) used technical assumptions on structural model which indicate standard properties of estimators based on quasi-maximum likelihood and Hermite expansion.

Bayesian approach has been applied in numerous fields for many years. Volatility models can be developed and estimated with Bayesian approach. Carlin, Polson and Stoffer (1992) used Bayesian approach to analyse state-space models and literature has expanded in time. Jacquier, Polson and Rossi (1994, JPR) were the first to use Bayesian Markov chain Monte Carlo (MCMC) method to examine SV models. Geweke (1994) used Bayesian importance sampling Monte Carlo Method, Kim, Shephard and Chib (1998) used Bayesian and maximum likelihood inference based on MCMC to estimate SV model. JPR (1994) and Kim et al. (1998) used single move Gibbs Sampler in their studies. Kim et al. (1998) used accept-reject sampling, Chib and Greenberg (1995) proposed independence chain Metropolis-Hastings (M-H) algorithm and accept-reject M-H algorithm methods for simulating volatility because of the conditional density of volatility is not in standard form. JPR (1994) combined accept-reject sampling with M-H algorithm.

Bayesian stochastic volatility (BSV) model with normal residuals can be used to analyse volatility. For the reason that financial series have fat-tails in the conditional distribution Nelson (1991) and Bollerslev (1997) suggested classical GARCH models which the conditional mean has fat tailed distribution. Geweke (1994c), Gallant, Hsieh, Tauchen (1997) proposed BSV models which the conditional mean has fat tailed distribution and estimated BSV models with fat-tailed residuals (BSVF) in the mean equation. Carlin and Polson (1991) set v degree of freedom constant. Harvey and Shephard (1996) offered SV model that includes leverage effect via correlation between the volatility and mean equation residual and named the model as asymmetric Bayesian SV model (ABSV).

Leverage effect is specified in two different ways in BSV models. One of those is the Euler Approach to BSV model with leverage effect which was suggested by Yu (2005) and the other one is the discrete time BSV model approach which was suggested by JPR (2004). JPR (2004) also estimated BSV models that allow both leverage effect and fattailed residuals (ABSVF). In this study, classical SV, BSV, BSVF, ABSV and ABSVF models are estimated for stock returns of developed and developing markets. The aim of this study is to examine which models can give better results for developed and developing market data by comparing the estimated results.

The contribution of this study to the literature is the estimation of bayesian stochastic volatility models that allow both leverage effect and fat-tailed residuals on the assumption that a decline in stock prices in period $t$ following an increase in stock return volatility in period $(\mathrm{t}+1)$ which has not been tried in the literature before. 


\section{Classical Stochastic Volatility Model:-}

On the assumption that constant mean, Taylor (1986) expresses asset return with the basic SV model in discrete time format,

$$
\begin{gathered}
y_{t}=\sigma_{t} \varepsilon_{t} \\
\log \sigma_{t}^{2}=\mu+\phi \log \sigma_{t-1}^{2}+\sigma_{\eta} \eta_{t} \\
\varepsilon_{t}, \eta_{t} \sim N(0,1), \quad t=1_{s, \ldots}, n
\end{gathered}
$$

here $\sigma_{t}$ is used instead of $\sigma_{t \mid t-1}$ for the reason that volatility can not completely identified conditional on $y_{1}, y_{2}, \ldots, y_{t-1}$ returns, $\varepsilon_{t}$ random variables are white noise (i.i.d.), $\phi$ is a parameter controlling the persistence of volatility and states how slowly autocorrelation decay and $-1<\phi<1$. $y_{t}$ return is distributed as a mixture with variance of $\eta_{t}$ variable. The number of unobservable parameters are as many as the sample size therefore model estimation becomes complicated.

In this study, EMM is used to estimate classical SV model. This method is generally provides consistent estimations in cases where implementation of maximum likelihood method is difficult (Gallant and Tauchen 1996). As EMM provides the elasticity of GMM, also provides the constitution of moments efficiently. An algorithm is used to obtain parameter estimations in EMM. Structural model is estimated with the aid of auxiliary model. The connection between the auxiliary model and the structural model is achieved by the means of the scores of the auxiliary model. The derivatives of logarithmic likelihood function respect to the parameters are named as "score". Assumptions that imply standard properties of quasi-maximum likelihood estimators and properties of estimators based on Hermite expansions are used on structural model (Gallant and Long 1997). The semi-nonparametric density is used for providing the efficiency of maximum likelihood (Gallant and Nychka 1987). The parameters of the auxiliary model are obtained by the EGARCH model of Nelson (1991).

\section{Bayesian Stochastic Volatility Model:-}

BSV model parameters can be estimated by two different MCMC approach. The first of those is "single-move sampler" which consists of updating a single parameter at a time. Second approach consists of updating several variables at a time and called "multi-move sampler". In this study "single-move sampler" is used in the analysis.

If logarithmic volatility at time $\mathrm{t}$ is represented as $h_{\mathrm{t}}$, BSV model with normal residuals can be written as,

$$
\begin{gathered}
y_{t}=\sqrt{h_{t}} \varepsilon_{t} \\
\log h_{\mathrm{t}}=\mu+\phi \log h_{\mathrm{t}-1}+\sigma_{\eta} \eta_{\mathrm{t}} \\
\varepsilon_{\mathrm{t},}, \eta_{\mathrm{t}} \sim N\left(0, I_{2}\right), \quad t=1_{, \ldots, n} n
\end{gathered}
$$

where $I_{2}$ is the two-dimensional unit matrix, $\mu$ is the intercept, $\phi$ is the volatility persistency and $\sigma_{\eta}$ is the standard deviation of the shock that occurs in $\log h_{\mathrm{t}}$. Likelihood function is,

$$
p(y \mid \theta)=\int p(y \mid h, \theta) p(h \mid \theta) d h
$$

where $y=\left(y_{1}, \ldots, y_{T}\right)$ and $h=\left(h_{1, \ldots,}, h_{T}\right)$ is the vector of latent volatility, $\theta=\left(\mu, \phi, \sigma_{\eta}^{2}\right)$ is the parameter vector. As $h_{t}$ is latent, analytical solution of $\mathrm{T}$ dimensional integral in likelihood function is very difficult.

BSV model can be determined with the three hierarchical process of three conditional distributions (JPR 1994). MCMC stand for the multidimensionality problem by breaking the joint posterior $p(\theta, h \mid y)$ into its complete set of 
conditional distributions (Kim et al. 1998). For the single-move Gibbs sampler, the complete set of full conditional distribution in other words full conditional posteriors are,

$$
\begin{gathered}
p\left(h_{t} \mid y, h_{-t}, \mu, \phi, \sigma_{\eta}^{2}\right), \quad t=1_{, \ldots,} T \\
p\left(\sigma_{\eta}^{2} \mid y, h_{s} \mu, \phi\right), p\left(\phi \mid y, h_{s} \sigma_{\eta}^{2}, \mu\right), \quad p\left(\mu \mid y, h, \phi, \sigma_{\eta}^{2}\right)
\end{gathered}
$$

where $h_{-t}$, shows the elements of $h=\left(h_{1, \ldots,}, h_{T}\right)$ excluding $h_{\mathrm{t}}$. Full conditional posteriors determine the joint posterior $p(\theta, h \mid y)$ with the Clifford-Hammersley Theorem. Here $\theta$ is the parameter vector $\theta=\left(\mu, \phi, \sigma_{\eta}^{2}\right)$.According to this theorem the joint posteriorp $(\theta, h \mid y)$ can be determined by its complete set of conditionals $p(\theta \mid y, h)$ and $p(h \mid \theta, y)$ therefore, primarily these conditional probabilities have to be determined (Meng 2009). The most difficult part of Gibbs sampler is to obtain $h_{t}$ from conditional distribution $p\left(h_{t} \mid h_{-t}, y_{v} \mu_{s} \phi, \sigma_{\eta}^{2}\right)$ (JPR 1994).

\section{Alternative Stochastic Volatility Models:-}

The estimation of SV models are more difficult than ARCH models. BSV model is restricting in terms of many economic and financial applications. The usage of this model can lead biased volatility forecasts especially in the high volatility periods. JPR (2004) developed BSV model that allows fat-tailed residuals (BSVF) in the mean equation, allows leverage effect via correlation between the volatility and mean equation residual (ABSV) and allows both leverage effect and fat-tailed residuals (ABSVF).

\section{Fat-tailed Bayesian Stochastic Volatility Model:-}

BSV model is inadequate to reflect the effects of outliers (Geweke 1994c). $\varepsilon_{t}$ probability distribution can become fat-tailed with scale mixture of normals by keeping the symmetry property. In this approach variable of scale mixture is the latent variable. BSVF model in the mean equation,

$$
\begin{gathered}
y_{\mathrm{t}}=\sqrt{h_{\mathrm{t}}} \varepsilon_{\mathrm{t}}=\sqrt{h_{\mathrm{t}}} \sqrt{\lambda_{\mathrm{t}} z_{\mathrm{t}}} \\
\log h_{\mathrm{t}}=\mu+\phi \log h_{\mathrm{t}-1}+\sigma_{\eta} \eta_{\mathrm{t}}, \quad t=1_{, \ldots,} T \\
\left(\mathrm{z}_{\mathrm{t}}, \eta_{\mathrm{t}}\right) \sim N_{2}(0, I), \lambda_{\mathrm{t}} \sim p\left(\lambda_{\mathrm{t}} \mid v\right) \\
p\left(\mu, \phi, \sigma_{\eta}, v\right)=p\left(\mu, \mu_{v} \sigma_{\eta}\right) p(v)
\end{gathered}
$$

The probability distributions $p\left(\lambda_{t} \mid v\right)$ and $p(v)$ are chosen to reflect the fat-tailed probability of $p\left(\varepsilon_{t}\right)$. Here $\lambda_{t}$ supposed to distribute as inverse-gamma independently and identically or $v \mid \lambda_{t} \sim \chi_{V}^{2}$. In this case the marginal distribution of $\varepsilon_{t}\left(\varepsilon_{t}=\sqrt{\lambda_{t}} z_{t}\right)$ is Student-t with $\mathrm{v}$ degree of freedom (JPR 1999). Prior distributions $p\left(\mu, \phi, \sigma_{\eta}\right)$ specified in BSV model are also used in here. Conjugate inverse gamma prior for $\left.\lambda_{t}\right|_{v}$ is identified as

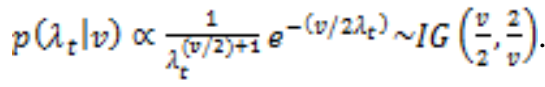

\section{Bayesian Stochastic Volatility Model with Leverage Effect:-}

Asymmetric response of volatility to stock price changes is known as "leverage effect" (Black and Scholes 1973). Positive variance shock has less effect on the conditional variance in comparison with negative shock. This negative correlation forms leverage effect. BSV model is expressed by Euler approach with stochastic difference equations in BSV model with leverage effect. ABSV model,

$$
\begin{gathered}
d s(t)=\sigma(t) d B_{1}(t) \\
d \log \sigma^{2}(t)=\mu+\phi \log \sigma^{2}(t) d t+\sigma_{\eta} d B_{2}(t)
\end{gathered}
$$

where $s(t)$ is the asset price and $\sigma^{2}(t)$ denotes volatility. $B_{1}(t)$ and $B_{2}(t)$ are Brownian motions. $\operatorname{corr}\left(d B_{1}(t), d B_{2}(t)\right)=\rho$ and $s(t)=\ln S(t)$. If $\rho<0$ than leverage effect is existent.In practice the representation above is become discrete in terms of easiness. ABSV model (Yu 2005), 


$$
\begin{gathered}
y_{t}=\sqrt{h_{t}} \varepsilon_{t} \\
\log h_{t+1}=\mu+\phi \log h_{t}+\sigma_{\eta} \eta_{t+1}
\end{gathered}
$$

where $y_{t}=s(t+1)-s(t)$ is the continuous return variable, $\varepsilon_{t}=B_{1}(t+1)-B_{1}(t), \eta_{t+1}=B_{2}(t+1)-B_{2}(t)$ and $\phi=1+\beta, h_{t}=\sigma_{t}^{2}$. Here $\varepsilon_{t}$ and $\eta_{t}$ are iid $\mathrm{N}(0,1)$. The relationship between $\varepsilon_{t}$ and $\eta_{t+1}$ is denoted with $\rho$ correlation coefficient. In this study the ABSV model that suggested by Yu (2005) is used in the application. Full conditional distributions are not log-concave in ABSV models therefore $\mathrm{M}-\mathrm{H}$ step is used in simulation and expressed as,

$$
\begin{gathered}
h_{\mathrm{t}+1} J h_{\mathrm{t},} \mu_{s} \phi, \sigma_{\eta}^{2} \sim N\left(\mu+\phi h_{\mathrm{t},} \sigma_{\eta}^{2}\right) \\
y_{\mathrm{t}} J h_{\mathrm{t}+1,}, h_{\mathrm{t},} \mu_{s}, \phi_{s} \sigma_{\eta}^{2}, \rho \sim N\left(\frac{\rho}{\sigma_{\eta}} e^{h_{\mathrm{t}} / 2}\left(h_{\mathrm{t}+1}-\mu-\phi h_{\mathrm{t}}\right), e^{h_{\mathrm{t}}}\left(1-\rho^{2}\right)\right)
\end{gathered}
$$

\section{Bayesian Stochastic Volatility Model That Allows Both Leverage Effect And Fat-Tailed Residuals:-} When correlated model is developed for including fat-tail property, the full model is,

$$
\begin{gathered}
y_{t}=\sqrt{h_{\mathrm{t}}} \varepsilon_{\mathrm{t}}=\sqrt{h_{\mathrm{t}} \lambda_{\mathrm{t}}} z_{\mathrm{t}} \\
\log h_{\mathrm{t}+1}=\mu+\phi \log h_{\mathrm{t}}+\sigma_{\eta} \eta_{\mathrm{t}+1}, \quad \nabla \mid \lambda_{\mathrm{t}} \sim \chi_{V}^{2} \\
\left(\mathrm{z}_{\mathrm{t},}, \eta_{\mathrm{t}+1}\right) \sim N\left(0,\left(\begin{array}{ll}
1 & \rho \\
\rho & 1
\end{array}\right)\right)
\end{gathered}
$$

with the priors $p\left(\mu, \phi, \sigma_{\eta}, v, \rho\right)$. The algorithm mentioned before can also be used here.

\section{Empirical Application:-}

Classical SV, BSV, BSVF and ABSVF models are estimated and compared for stock returns of developed and developing 10 countries.

\section{Data:-}

In the study Argentina, Brasil, China, Mexico and Turkey are taken as the stock returns of developing markets, United Kingdom, France, Germany, United States and Japan are taken as the stock returns of developed markets ${ }^{1}$.

The daily return series of BOVESPA (BVSP) (Brasil), HANGSENG (HSI) (China), IPC (Mexico), Istanbul stock exchange 100 (ISE 100) (Turkey), FTSE 100 (UK), CAC 40 (France), DAX (Germany), S\&P 500 (US), NIKKEI 225 (Japan) indexes are used between the dates 04.01.1995-18.06.2010. Only the initial date of MERVAL (MERV) (Argentina) is $09.10 .1996^{2}$. Return series $\left(y_{t}\right)$ are calculated with the formula $y_{t}=\left(\log p_{t}-\log p_{t-1}\right) * 100$ where $p_{t}$ denotes closing price of index at the day $t, p_{t-1}$ denotes closing price of index at the day $(t-1)$.

The descriptive statistics of return series are reported in Table 1. When examining the means of series it is seen that all of them are around zero. ISE 100 index has the maximum mean with the value of 0.14, BVSP and IPC are following respectively. The means of all return series are positive except NIKKEI. Skewness of the BVSP, HSI, IPC, CAC return series are skewed to the right, the others are skewed to the left. Kurtosis of all series are sharply indicating the distributions have fat-tails. According to the Jarque-Bera Test none of the series distributed as normal.

\footnotetext{
${ }^{1}$ http://www.ams.org/membership/individual/types/mem-develop and http://www.icce2010.org/docs/developingCountries.pdf
} ${ }^{2} \mathrm{http}: / /$ finance.yahoo.com/intlindices?e=americas 
Table 1:- Descriptive Statistics of Return Series

\begin{tabular}{|c|c|c|c|c|c|c|c|c|c|c|}
\hline & Me. & Med. & Max. & Min. & SD & SK & KU & JB & Prob. & $\mathbf{N}$ \\
\hline MERV & 0.04 & 0.1 & 16.12 & -14.76 & 2.26 & -0.25 & 8.34 & 4057.05 & 0.00 & 3384 \\
\hline BVSP & 0.07 & 0.14 & 28.83 & -17.21 & 2.38 & 0.48 & 15.16 & 23680.49 & 0.00 & 3821 \\
\hline HSI & 0.02 & 0.04 & 17.25 & -14.73 & 1.79 & 0.11 & 12.42 & 14206.94 & 0.00 & 3839 \\
\hline IPC & 0.07 & 0.09 & 12.15 & -14.31 & 1.67 & 0.04 & 8.71 & 5268.82 & 0.00 & 3873 \\
\hline ISE & 0.14 & 0.15 & 17.77 & -19.98 & 2.74 & -0.04 & 7.65 & 3460.65 & 0.00 & 3841 \\
\hline FTSE & 0.01 & 0.06 & 9.38 & -9.26 & 1.23 & -0.13 & 9.09 & 6042.73 & 0.00 & 3904 \\
\hline CAC & 0.02 & 0.05 & 10.59 & -9.47 & 1.49 & 0.01 & 7.81 & 3781.94 & 0.00 & 3921 \\
\hline DAX & 0.03 & 0.09 & 10.8 & -7.43 & 1.56 & -0.05 & 7.12 & 2768.18 & 0.00 & 3914 \\
\hline S\&P & 0.02 & 0.07 & 10.96 & -9.47 & 1.28 & -0.2 & 10.97 & 10320.95 & 0.00 & 3893 \\
\hline NIKKEI & -0.02 & 0 & 13.23 & -12.11 & 1.58 & -0.19 & 8.28 & 4438.3 & 0.00 & 3800 \\
\hline
\end{tabular}

*Me; mean, Med;median, Max;maximum, Min;minimum, SD; standard deviation, SK; skewness, KU; kurtosis,

JB; Test statistics of Jarque-Bera, Prob; probabillity value of JB Test, N; the number of observations.

\section{Estimation Results:-}

To estimate the classical SV model by EMM first of all auxiliary model based on semi-nonparametric density has to be determined. The results of EMM estimation is in Table 2.

Table 2:- The results of EMM estimation of Classical SV model

\begin{tabular}{|c|c|c|c|c|c|c|c|c|c|c|}
\hline & EG & EG & $\mathrm{EG}$ & $\mathrm{EG}$ & EG & EG & $\mathrm{EG}$ & EG & $\mathrm{EG}$ & EG \\
\hline & $\begin{array}{l}(1,1)- \\
H(8,0)\end{array}$ & $\begin{array}{l}(1,1)- \\
H(9,0)\end{array}$ & $\begin{array}{l}(1,1)- \\
H(9,0)\end{array}$ & $\begin{array}{l}(1,1)- \\
H(3,0)\end{array}$ & $\begin{array}{c}(1,1)- \\
\mathrm{H}(10,0)\end{array}$ & $\begin{array}{c}(1,1)- \\
\mathrm{H}(10,0)\end{array}$ & $\begin{array}{l}(1,3)- \\
H(5,0)\end{array}$ & $\begin{array}{l}(1,1)- \\
H(2,0)\end{array}$ & $\begin{array}{l}(1,1)- \\
H(2,0)\end{array}$ & $\begin{array}{l}(1,1)- \\
H(9,0)\end{array}$ \\
\hline & MERV & BV & HSI & IPC & ISE & FTSE & CAC & DAX & S\&P & NK \\
\hline J-Test & 66.92 & 133.31 & 33.82 & 71.74 & 28.45 & 1803.0 & 29.68 & 32.83 & 140.13 & 56.63 \\
\hline df & 10 & 11 & 11 & 5 & 12 & 12 & 9 & 4 & 4 & 11 \\
\hline$\chi^{2}$ & 18.31 & 19.68 & 19.68 & 11.07 & 21.03 & 21.03 & 16.92 & 9.49 & 9.49 & 19.68 \\
\hline \multicolumn{11}{|c|}{ T statistics of J Test for the Auxiliary Model Parameters } \\
\hline$\alpha_{0}$ & -0.39 & -1.03 & 0.27 & 2.03 & 1.26 & -5.43 & 0.45 & 4.68 & -2.11 & -1.03 \\
\hline$\alpha_{1}$ & 1.07 & -2.50 & -1.91 & -4.84 & -0.22 & 3.00 & 0.82 & -5.43 & -7.97 & -4.89 \\
\hline$\alpha_{2}$ & & & & & & & 1.31 & & & \\
\hline$\alpha_{a}$ & & & & & & & -0.13 & & & \\
\hline$\gamma_{1}$ & 0.84 & -0.35 & -1.58 & -4.00 & -0.17 & -1.60 & 0.72 & -3.42 & -6.31 & -4.78 \\
\hline$\kappa_{1}$ & -0.03 & 1.04 & 1.69 & 6.63 & 1.36 & 9.72 & 0.04 & 5.27 & 11.18 & 5.74 \\
\hline$\kappa_{1}$ & 0.84 & -0.61 & -0.87 & 0.64 & -0.59 & 19.94 & 1.43 & -3.23 & 5.07 & -0.04 \\
\hline a 10 & -1.61 & -3.33 & -1.15 & -3.34 & -3.43 & 0.65 & -2.90 & -2.03 & -1.48 & 0.03 \\
\hline a 20 & -1.32 & -5.30 & -0.57 & 1.21 & 0.14 & -1.59 & 1.40 & 2.29 & -5.67 & -2.97 \\
\hline a 30 & 1.28 & 0.67 & 0.62 & 2.43 & 1.24 & 6.93 & -0.61 & & & 3.05 \\
\hline a 40 & 1.50 & -0.25 & 0.00 & & -0.37 & 17.35 & 1.89 & & & 0.20 \\
\hline a 50 & 1.48 & -1.53 & 0.17 & & 1.57 & -3.72 & -3.71 & & & -0.24 \\
\hline a 60 & 0.04 & -1.66 & 2.68 & & -2.53 & -10.24 & & & & 0.19 \\
\hline a 70 & 1.51 & 1.85 & 0.07 & & -0.68 & -4.58 & & & & -1.30 \\
\hline a 80 & 1.84 & 1.93 & -1.12 & & -0.33 & 3.45 & & & & -2.94 \\
\hline a 90 & & 1.87 & -0.06 & & -1.01 & -0.13 & & & & 1.30 \\
\hline a10 0 & & & & & -0.89 & 4.75 & & & & \\
\hline \multicolumn{11}{|c|}{ Estimated Parameter Values and t-Statistics of Structural Model } \\
\hline$\mu$ & 0.07 & 0.17 & 0.09 & 0.14 & 0.12 & -0.09 & 0.06 & 0.02 & -0.001 & 0.01 \\
\hline$(\mathrm{t})$ & 0.008 & 0.008 & 0.032 & 25.64 & 0.076 & -0.009 & 0.33 & 1.76 & -0.61 & 0.36 \\
\hline$\phi$ & 0.92 & 0.83 & 0.84 & 0.80 & 0.92 & 0.93 & 0.81 & 0.96 & 0.97 & 0.97 \\
\hline$(\mathrm{t})$ & 0.05 & 0.10 & 0.306 & 236.8 & 0.30 & 0.024 & 1.64 & 123.6 & 4283.8 & 59.87 \\
\hline$\sigma_{\eta \eta}$ & 0.51 & 0.41 & 0.29 & 0.36 & 0.34 & 0.43 & 0.40 & 0.15 & 0.01 & 0.13 \\
\hline$(\mathrm{t})$ & 0.11 & 0.097 & 0.201 & 89.35 & 0.27 & 0.052 & 5.97 & 27.04 & 16.06 & 13.35 \\
\hline
\end{tabular}


* "EG" denotes EGARCH. Df is the degree of freedom, $\alpha_{\mathrm{i}}$ is the short-run response to the shocks, $\gamma_{1}$ is persistency, $\kappa_{1}$ is the asymmetric volatility effect, $\kappa_{2}$ denotes the changes in standardised process.

Table 2 contains estimation results of the auxiliary models EGARCH $(1,1)-\mathrm{H}(\mathrm{Kx}, 0)$, EGARCH $(1,2)-\mathrm{H}(\mathrm{Kx}, 0)$, EGARCH $(1,3)-\mathrm{H}(\mathrm{Kx}, 0)$ and EGARCH $(1,1)-\mathrm{H}(\mathrm{Kx}, 1)$ for all return series and the best models are chosen by comparing the values of logarithmic likelihood, AIC, Schwarz and Hannan-Quinn Criteria. The selected auxiliary models are: MERV-EGARCH(1,1)-H(8,0), BVSP-EGARCH $(1,1)-\mathrm{H}(9,0), \quad$ HSI-EGARCH( 1,1$)-\mathrm{H}(9,0)$, IPCEGARCH(1,1)-H(3,0), ISE-EGARCH(1,1)-H(10,0), FTSE-EGARCH(1,1)-H(10,0), CAC-EGARCH(1,3)-H(5,0), DAX-EGARCH(1,1)-H(2,0), S\&P-EGARCH(1,1)-H(2,0), NIKKEI-EGARCH(1,1)-H(9,0).

Strong convergences are provided in all the auxiliary and structural model estimations. J Test results of structural models are notably high for each series (Gallant et al. 1997). This is commonly encountered in the EMM literature. In this situation decision is made by the results of t statistics of the auxiliary model parameters (Van der Sluis 1998). When examining the $t$ statistics of the auxiliary model parameters for $\mathbf{J}$ Test, the zero hypothesis that defends model is valid is accepted for each series except S\&P return index because of the statistics of $\kappa_{1}$ parameter is larger than the critical value.

Structural model estimates show that structural model parameters for IPC is statistically significant for the error rate 5 $\%$, for DAX is statistically significant for the error rate $10 \%$. In consequence only these two models are interpreted. Considering the results of structural models for IPC and DAX, it is seen that persistency parameters are very high with the value of 0.80 and 0.96 , respectively.

It is very crucial to determine priors in Bayesian approach. Like Meyer and $\mathrm{Yu}(2000)$ in this study the priors that Kim et al. (1998) suggested are used. As market stock return series have different forms, they may also have different priors. For the determination of prior parameters first of all beta distribution parameters which gives minimum DIC value for the estimated BSV model are determined for each stock return. After that in the same way gamma parameters and normal distribution parameters are determined. Uniform $(0,1)$ prior is also tried for $\phi$ persistency parameter, but the required result can not be obtained. The new mean values are determined by adding $\mp 1 \sigma, \bar{\mp} 0.5 \sigma$ and $\bar{\mp} 1.5 \sigma$ to the mean of the distribution and with these new mean values the distribution parameters are obtained coinciding with the previous standard deviation. Model is reestimated with these new parameter values and the parameters that give minimum DIC values are selected as proper parameter values with 10000 iterations. The priors and distribution parameters that make DIC value minimum through tried models take part in Table 3 .

Table 3:- The Prior Parameters Determined for Persistency $\phi$ and $\sigma_{\eta}^{2}$ Parameter

\begin{tabular}{|l|l|l|}
\hline & For $\phi$ Parameter & For $\sigma_{m}^{2}$ Parameter \\
\hline MERV & beta(20,3.2) & Inverse gamma $(2,0.025)$ \\
\hline BVSP & beta $(20,3.2)$ & Inverse gamma $(2.5,0.025)$ \\
\hline HSI & beta $(26.44,2.83)$ & Inverse gamma $(2.5,0.025)$ \\
\hline IPC & beta $(20,1.5)$ & Inverse gamma $(2.5,0.025)$ \\
\hline ISE & beta $(20,3.2)$ & Inverse gamma $(2,0.025)$ \\
\hline FTSE & beta(20,1.5) & Inverse gamma $(2.5,0.025)$ \\
\hline CAC & beta(20,1.5) & Inverse gamma $(2.5,0.025)$ \\
\hline DAX & beta(20,1.5) & Inverse gamma $(2.5,0.025)$ \\
\hline S\&P & beta(32.02, 4.51) & Inverse gamma $(3,0.025)$ \\
\hline NK & beta(20,1.5) & Inverse gamma $(2.5,0.025)$ \\
\hline
\end{tabular}

*Because of it provides minimum DIC value for all models $\mu \sim N(0,10)$ is obtained.

After determining the priors, initial values have to be defined. WinBUGS 1.4.3 is used in the application. At first models are estimated by simulation with 10000 iterations without specifying the initial values of the parameters, after that the posterior means of parameters are taken as initial values. $\rho$ is defined as correlation $\left(\varepsilon_{\mathrm{t}}, \eta_{\mathrm{t}+1}\right)$ and distributed as uniform in ABSV model. $\beta, \phi$ and $\sigma_{\eta}$ parameters are estimated at first with 50000 next 100000 
iterations, but according to the results of Raftery and Lewis (1992) Diagnostic Test for providing convergence 1000000 iterations are needed therefore models are estimated with 1000000 iterations.

Autocorrelation graphs and Pearson correlation coefficients of the values following each other in the chain are also examined. High autocorrelation indicates taking long time for reaching the posterior of the parameter. Even the size of correlations affect the convergence speed of the sampling algorithm, it does not affect convergence in anyway. Table $4 \mathrm{a}$ and $4 \mathrm{~b}$ in the below present posterior means of the model parameters estimated with 1000000 iterations.

Table 4a:- Estimation Results of the Bayesian Models for Developing Markets.

\begin{tabular}{|c|c|c|c|c|c|}
\hline & & BSV & BSVF & ABSV & ABSVF \\
\hline & $\beta$ & $\begin{array}{l}1.7460(0.0007) \\
(1.5630,1.9430)\end{array}$ & $\begin{array}{l}1.6130(0.0013) \\
(1.4150,1.8220)\end{array}$ & $\begin{array}{l}1.7440(0.0006) \\
(1.5570,1.9430)\end{array}$ & $\begin{array}{l}1.6060(0.0008) \\
(1.4050,1.8140)\end{array}$ \\
\hline \multirow[t]{5}{*}{$\mathrm{ME}$} & $\phi$ & $\begin{array}{l}0.9560(0.0002) \\
(0.9380,0.9713)\end{array}$ & $\begin{array}{l}0.9683(0.0002) \\
(0.9529,0.9810)\end{array}$ & $\begin{array}{l}0.9590(0.0002) \\
(0.9420,0.9731)\end{array}$ & $\begin{array}{l}0.9701(0.0002) \\
(0.9555,0.9819)\end{array}$ \\
\hline & $\sigma_{m}$ & $\begin{array}{l}0.2692(0.0007) \\
(0.2233,0.3201)\end{array}$ & $\begin{array}{l}0.2161(0.0009) \\
(0.1723,0.2643)\end{array}$ & $\begin{array}{l}0.2526(0.0007) \\
(0.2117,0.2994)\end{array}$ & $\begin{array}{l}0.2058(0.0008) \\
(0.1650,0.2519)\end{array}$ \\
\hline & $\rho$ & & & $\begin{array}{c}-0.0017(0.0031)(- \\
0.9504,0.9510)\end{array}$ & $\begin{array}{c}0.0015(0.0042) \\
(-0.9460,0.9534)\end{array}$ \\
\hline & $\mathrm{CV}^{2}$ & 1.3211 & 1.1137 & 1.2132 & 1.0524 \\
\hline & $\beta$ & $\begin{array}{l}1.9790(0.0013) \\
(1.7570,2.2650)\end{array}$ & $\begin{array}{l}1.9390(0.0029) \\
(1.7030,2.2670)\end{array}$ & $\begin{array}{l}1.9970(0.0016) \\
(1.7660,2.3090)\end{array}$ & $\begin{array}{l}1.9580(0.0024) \\
(1.7090,2.3480)\end{array}$ \\
\hline \multirow[t]{5}{*}{ BV } & $\phi$ & $\begin{array}{l}0.9742(0.0001) \\
(0.9629,0.9843)\end{array}$ & $\begin{array}{l}0.9786(0.0001) \\
(0.9678,0.9881)\end{array}$ & $\begin{array}{l}0.9768(0.0001) \\
(0.9660,0.9865)\end{array}$ & $\begin{array}{l}0.9806(0.0001) \\
(0.9705,0.9899)\end{array}$ \\
\hline & $\sigma_{\eta 习}$ & $\begin{array}{l}0.1840(0.0005) \\
(0.1552,0.2158)\end{array}$ & $\begin{array}{c}0.1644(0.0005) \\
(0.1356,0.1974)\end{array}$ & $\begin{array}{l}0.1685(0.0005) \\
(0.1424,0.1974)\end{array}$ & $\begin{array}{l}0.1533(0.0005) \\
(0.1267,0.1821)\end{array}$ \\
\hline & $\rho$ & & & $\begin{array}{l}-0.0077(0.0038) \\
(-0.9486,0.9527) \\
\end{array}$ & $\begin{array}{c}0.0025(0.0033) \\
(-0.9489,0.9499) \\
\end{array}$ \\
\hline & $\mathrm{CV}^{2}$ & 0.9439 & 0.8932 & 0.8572 & 0.8434 \\
\hline & $\beta$ & $\begin{array}{l}1.4750(0.0024) \\
(1.2130,1.8380)\end{array}$ & $\begin{array}{l}1.4080(0.0040) \\
(1.1290,1.8230)\end{array}$ & $\begin{array}{l}1.4750(0.0014) \\
(1.2100,1.8420)\end{array}$ & $\begin{array}{l}1.4060(0.0012) \\
(1.1300,1.8050)\end{array}$ \\
\hline \multirow[t]{5}{*}{ HS } & $\phi$ & $\begin{array}{l}0.9900(0.0001) \\
(0.9842,0.9951)\end{array}$ & $\begin{array}{l}0.9929(0.0001) \\
(0.9882,0.9969)\end{array}$ & $\begin{array}{l}0.9901 \quad(0.0001) \\
(0.9841,0.9951)\end{array}$ & $\begin{array}{l}0.9929(0.0000) \\
(0.9881,0.9969) \\
\end{array}$ \\
\hline & $\sigma_{\eta}$ & $\begin{array}{l}0.1288(0.0005) \\
(0.1065,0.1534)\end{array}$ & $\begin{array}{l}0.1066(0.0005) \\
(0.0867,0.1297)\end{array}$ & $\begin{array}{l}0.1286(0.0004) \\
(0.1071,0.1531)\end{array}$ & $\begin{array}{l}0.1068(0.0004) \\
(0.0871,0.1291)\end{array}$ \\
\hline & $\rho$ & & & $\begin{array}{l}-0.0010(0.0043) \\
(-0.9501,0.9519)\end{array}$ & $\begin{array}{c}0.0068(0.0031) \\
(-0.9506,0.9521)\end{array}$ \\
\hline & $\mathrm{CV}^{2}$ & 1.301 & 1.2325 & 1.3149 & 1.2392 \\
\hline & $\beta$ & $\begin{array}{l}1.4390(0.0014) \\
(1.2680,1.6710)\end{array}$ & $\begin{array}{l}1.4330(0.0093) \\
(1.2040,1.9770)\end{array}$ & $\begin{array}{l}1.4400(0.0014) \\
(1.2700,1.6680)\end{array}$ & $\begin{array}{l}1.4270(0.0047) \\
(1.2070,1.9010)\end{array}$ \\
\hline \multirow[t]{5}{*}{ IP } & $\phi$ & $\begin{array}{l}0.9736(0.0002) \\
(0.9601,0.9852)\end{array}$ & $\begin{array}{l}0.9817(0.0002) \\
(0.9695,0.9945)\end{array}$ & $\begin{array}{l}0.9737(0.0002) \\
(0.9605,0.9851)\end{array}$ & $\begin{array}{l}0.9819(0.0002) \\
(0.9703,0.9938)\end{array}$ \\
\hline & $\sigma_{\eta}$ & $\begin{array}{l}0.1981(0.0007) \\
(0.1615,0.2396)\end{array}$ & $\begin{array}{l}0.1605(0.0009) \\
(0.1235,0.2021)\end{array}$ & $\begin{array}{l}0.1975(0.0007) \\
(0.1608,0.2372)\end{array}$ & $\begin{array}{l}0.1595(0.0008) \\
(0.1246,0.1978)\end{array}$ \\
\hline & $\rho$ & & & $\begin{array}{c}0.0027(0.0041) \\
(-0.9540,0.9476)\end{array}$ & $\begin{array}{c}0.0000(0.0030) \\
(-0.9531,0.9525)\end{array}$ \\
\hline & $\mathrm{CV}^{2}$ & 1.1238 & 1.0347 & 1.1201 & 1.0323 \\
\hline & $\beta$ & $\begin{array}{l}2.2080(0.0009) \\
(1.9740,2.4560)\end{array}$ & $\begin{array}{l}2.1020(0.0016) \\
(1.8460,2.3630)\end{array}$ & $\begin{array}{l}2.2040(0.0007) \\
(1.9610,2.4600)\end{array}$ & $\begin{array}{l}2.0870(0.0009) \\
(1.8270,2.3580)\end{array}$ \\
\hline \multirow[t]{4}{*}{ IS } & $\phi$ & $\begin{array}{l}0.9664(0.0002) \\
(0.9513,0.9787)\end{array}$ & $\begin{array}{l}0.9748(0.0002) \\
(0.9620,0.9854)\end{array}$ & $\begin{array}{l}0.9701(0.0002) \\
(0.9568,0.9812)\end{array}$ & $\begin{array}{l}0.9770(0.0002) \\
(0.9652,0.9868)\end{array}$ \\
\hline & $\sigma_{\eta p}$ & $\begin{array}{l}0.2200(0.0007) \\
(0.1821,0.2642)\end{array}$ & $\begin{array}{c}0.1826((0.0008)) \\
(0.1437,0.2235)\end{array}$ & $\begin{array}{l}0.2008(0.0006) \\
(0.1678,0.2380)\end{array}$ & $\begin{array}{l}0.1703(0.0008) \\
(0.1358,0.2084)\end{array}$ \\
\hline & $\rho$ & & & $\begin{array}{c}0.0009(0.0031) \\
(-0.9458,0.9498)\end{array}$ & $\begin{array}{c}0.0045(0.0032) \\
(-0.9512,0.9518)\end{array}$ \\
\hline & $\mathrm{CV}^{2}$ & 1.0804 & 0.9542 & 0.9828 & 0.8923 \\
\hline
\end{tabular}


Table 4b:- Estimation Results of the Bayesian Models for Developed Markets.

\begin{tabular}{|c|c|c|c|c|c|}
\hline & & BSV & BSVF & ABSV & ABSVF \\
\hline & $\beta$ & $\begin{array}{l}0.8954(0.0013) \\
(0.6942,1.0950)\end{array}$ & $\begin{array}{l}0.8688(0.0014) \\
(0.6733,1.0630)\end{array}$ & $\begin{array}{l}0.8960(0.0007) \\
(0.6987,1.0950)\end{array}$ & $\begin{array}{l}0.8678(0.0007) \\
(0.6709,1.0650)\end{array}$ \\
\hline \multirow[t]{5}{*}{ FT } & $\phi$ & $\begin{array}{l}0.9906(0.0001) \\
(0.9846,0.9959)\end{array}$ & $\begin{array}{l}0.9914(0.0001) \\
(0.9857,0.9963)\end{array}$ & $\begin{array}{l}0.9906(0.0001) \\
(0.9848,0.9958)\end{array}$ & $\begin{array}{l}0.9913(0.0001) \\
(0.9857,0.9962)\end{array}$ \\
\hline & $\sigma_{\eta \eta}$ & $\begin{array}{l}0.1303(0.0005) \\
(0.1073,0.1550)\end{array}$ & $\begin{array}{l}0.1240(0.0004) \\
(0.1028,0.1476)\end{array}$ & $\begin{array}{l}0.1298(0.0004) \\
(0.1081,0.1539)\end{array}$ & $\begin{array}{l}0.1244(0.0004) \\
(0.1037,0.1481)\end{array}$ \\
\hline & $\rho$ & & & $\begin{array}{l}0.0006(0.0031) \\
(-0.9499,0.9517)\end{array}$ & $\begin{array}{c}0.0014(0.0032) \\
(-0.9496,0.9480)\end{array}$ \\
\hline & $\mathrm{CV}^{2}$ & 1.4778 & 1.4542 & 1.4606 & 1.4431 \\
\hline & $\beta$ & $\begin{array}{l}1.198(0.0018) \\
(0.9843,1.432)\end{array}$ & $\begin{array}{l}1.1460(0.0016) \\
(0.9328,1.3740)\end{array}$ & $\begin{array}{l}1.1910(0.0006) \\
(0.9774,1.4220)\end{array}$ & $\begin{array}{l}1.1490(0.0006) \\
(0.9364,1.3810)\end{array}$ \\
\hline \multirow[t]{5}{*}{$\mathrm{CA}$} & $\phi$ & $\begin{array}{c}0.9898(0.00008) \\
(0.9837,0.9951)\end{array}$ & $\begin{array}{l}0.9912(0.0001) \\
(0.9855,0.9960)\end{array}$ & $\begin{array}{l}0.9899(0.0001) \\
(0.9839,0.9952)\end{array}$ & $\begin{array}{l}0.9911 \quad(0.0001) \\
(0.9853,0.9960)\end{array}$ \\
\hline & $\sigma_{\eta \eta}$ & $\begin{array}{l}0.1205(0.0005) \\
(0.1003,0.1435)\end{array}$ & $\begin{array}{c}0.1112 *(0.0004) \\
(0.0919,0.1339)\end{array}$ & $\begin{array}{l}0.1202(0.0004) \\
(0.1004,0.1419)\end{array}$ & $\begin{array}{c}0.1116(0.0004) \\
(0.0920,0.1336)\end{array}$ \\
\hline & $\rho$ & & & $\begin{array}{l}-0.0034(0.0031) \\
(-0.9467,0.9508)\end{array}$ & $\begin{array}{l}-0.0075(0.0029) \\
(-0.9518,0.9484)\end{array}$ \\
\hline & $\mathrm{CV}^{2}$ & 1.045 & 1.0252 & 1.0521 & 1.0194 \\
\hline & $\beta$ & $\begin{array}{c}1.127(0.0022) \\
(0.8497,1.3750)\end{array}$ & $\begin{array}{l}1.0760(0.0024) \\
(0.7821,1.3270)\end{array}$ & $\begin{array}{l}1.1300(0.0011) \\
(0.8519,1.3750)\end{array}$ & $\begin{array}{l}1.0720(0.0011) \\
(0.7791,1.3210)\end{array}$ \\
\hline \multirow[t]{5}{*}{ DA } & $\phi$ & $\begin{array}{l}0.9897(0.0001) \\
(0.9834,0.9956)\end{array}$ & $\begin{array}{l}0.9910(0.0001) \\
(0.9852,0.9965)\end{array}$ & $\begin{array}{l}0.9897(0.0001) \\
(0.9834,0.9954)\end{array}$ & $\begin{array}{l}0.9911(0.0001) \\
(0.9853,0.9965)\end{array}$ \\
\hline & $\sigma_{\eta \eta}$ & $\begin{array}{l}0.1356(0.0004) \\
(0.1139,0.1601)\end{array}$ & $\begin{array}{l}0.1264(0.0005) \\
(0.1042,0.1501)\end{array}$ & $\begin{array}{l}0.1357(0.0004) \\
(0.1157,0.1595)\end{array}$ & $\begin{array}{l}0.1256(0.0004) \\
(0.1053,0.1487)\end{array}$ \\
\hline & $\rho$ & & & $\begin{array}{l}0.0040(0.0039) \\
(-0.9477,0.9508)\end{array}$ & $\begin{array}{l}0.0008(0.0030) \\
(-0.9501,0.9520)\end{array}$ \\
\hline & $\mathrm{CV}^{2}$ & 1.4528 & 1.4390 & 1.456 & 1.4357 \\
\hline & $\beta$ & $\begin{array}{l}0.8804(0.0014) \\
(0.6696,1.0630)\end{array}$ & $\begin{array}{l}0.8038(0.0023) \\
(0.5631,0.9950)\end{array}$ & $\begin{array}{l}0.8786(0.0010) \\
(0.6642,1.0610)\end{array}$ & $\begin{array}{l}0.7985(0.0015) \\
(0.5478,0.9914)\end{array}$ \\
\hline \multirow[t]{5}{*}{ SP } & $\phi$ & $\begin{array}{l}0.9886(0.0001) \\
(0.9822,0.9943)\end{array}$ & $\begin{array}{c}0.9907 *(0.0001) \\
(0.9847,0.9961)\end{array}$ & $\begin{array}{l}0.9887(0.0001) \\
(0.9822,0.9945)\end{array}$ & $\begin{array}{l}0.9910(0.0001) \\
(0.9850,0.9964)\end{array}$ \\
\hline & $\sigma_{\eta \eta}$ & $\begin{array}{l}0.1394(0.0004) \\
(0.1173,0.1645)\end{array}$ & $\begin{array}{l}0.1252(0.0005) \\
(0.1026,0.1505)\end{array}$ & $\begin{array}{l}0.1388(0.0005) \\
(0.1142,0.1654)\end{array}$ & $\begin{array}{l}0.1228(0.0005) \\
(0.0991,0.1498)\end{array}$ \\
\hline & $\rho$ & & & $\begin{array}{l}-0.0024(0.0033) \\
(-0.9512,0.9500)\end{array}$ & $\begin{array}{c}0.0007(0.0029) \\
(-0.9464,0.9508)\end{array}$ \\
\hline & $\mathrm{CV}^{2}$ & 1.3565 & 1.3319 & 1.3568 & 1.3199 \\
\hline & $\beta$ & $\begin{array}{l}1.3290(0.0009) \\
(1.1700,1.5050)\end{array}$ & $\begin{array}{l}1.2580(0.0014) \\
(1.0870,1.4370)\end{array}$ & $\begin{array}{l}1.3290(0.0005) \\
(1.1680,1.5030)\end{array}$ & $\begin{array}{l}1.2610(0.0005) \\
(1.0870,1.4450)\end{array}$ \\
\hline \multirow[t]{4}{*}{$\mathrm{NI}$} & $\phi$ & $\begin{array}{l}0.9806(0.0001) \\
(0.9709,0.9888)\end{array}$ & $\begin{array}{l}0.9843(0.0001) \\
(0.9759,0.9916)\end{array}$ & $\begin{array}{c}0.9810^{*}(0.0001) \\
(0.9714,0.9892)\end{array}$ & $\begin{array}{l}0.9843(0.0001) \\
(0.9757,0.9918)\end{array}$ \\
\hline & $\sigma_{\eta \eta}$ & $\begin{array}{l}0.1448(0.0005) \\
(0.1210,0.1728)\end{array}$ & $\begin{array}{l}0.1279(0.0005) \\
(0.1032,0.1544)\end{array}$ & $\begin{array}{c}0.1429 *(0.0005) \\
(0.1183,0.1705)\end{array}$ & $\begin{array}{l}0.1274(0.0005) \\
(0.1028,0.1544)\end{array}$ \\
\hline & $\rho$ & & & $\begin{array}{l}-0.0050(0.003) \\
(-0.9507,0.9476)\end{array}$ & $\begin{array}{l}-0.0008(0.0031) \\
(-0.9451,0.9489)\end{array}$ \\
\hline & $\mathrm{CV}^{2}$ & 0.7258 & 0.6906 & 0.7204 & 0.6837 \\
\hline
\end{tabular}

*The Geweke statistics of these parameters are not significant so the estimated models involving these parameters are left out of assessment.

In the Table $4 \mathrm{a}$ and $4 \mathrm{~b}$ the expressions in the brackets at the same line show the MC simulation errors of estimations. The expressions in the brackets at the low line indicate the $2.5^{\text {th }}$ and $97.5^{\text {th }}$ quantiles of posteriors of parameters. $\mathrm{CV}^{2}$ is a variability measure of volatility and expressed as the squared coefficient of variation of the volatility process, 
computed as in JPR (1994). MC error shows the standard error of the estimation obtained by Markov chain algorithm and has to be small as for as possible $(<0.05)$.

When examining the results of BSV model in Table $4 \mathrm{a}$ and $4 \mathrm{~b}$, it is seen that beta parameter value of ISE index has the maximum posterior mean with the value of 2.208 , S\&P has the minimum posterior mean with the value of 0.8804 in all stock returns. Posterior means of phi persistency parameters are between the range of 0.956 and 0.9906 again in all the stock returns, displaying high persistency in conditional variance as in the estimations in ARCH literature. Persistency parameter of HSI is considerably higher comparing to other developing market stock returns with the posterior mean of 0.99 in Table 4a. BVSP, IPC and ISE are following HSI respectively. In Table 4b it is seen that the posterior means of persistency parameters for developed market stock returns are too close to each other and about 0.98, FTSE has the maximum posterior mean of persistency parameter with the value of 0.9906 in all the stock returns. Unit root in volatility do not exist in all the series. When examining variability of volatility, FTSE has the maximum variability with the value of 1.4778 in all the stock returns. DAX, S\&P, MERV and HSI are following FTSE with the values of 1.4528, 1.3565, 1.3211, 1.301 respectively. The stock return which has the minimum variability is NIKKEI with the value of 0.7258 . The high variability represents high risk and high return values. The variability in upper quantiles are much more greater than lower quantiles for all the stock returns.

When looking at the results of BSVF model in Table $4 \mathrm{a}$ and $4 \mathrm{~b}$, it is seen that the highest and the lowest posterior means of beta parameter are belong to ISE and S\&P as in the results of BSV model. Posterior mean of phi persistency parameters are between the range of 0.9683 and 0.99 in all the stock returns, displaying high persistency in conditional variance as in the results of BSV model. Persistency parameter of HSI is considerably higher comparing to other developing market stock returns as in the results of BSV model with the posterior mean of 0.9929 in Table 4a. IPC, BVSP, ISE and MERV are following HSI respectively. In Table $4 \mathrm{~b}$ it is seen that the posterior means of persistency parameters for developed market stock returns are too close to each other and NIKKEI has the minimum posterior mean of persistency parameter with the value of 0.9843 . When examining the posterior means of persistency parameters on the basis of all markets generally, HSI has the highest posterior mean. Unit root in volatility do not exist in all the series. FTSE has the maximum variability of volatility as in the BSV model with the value of 1.4542. NIKKEI has the minimum variability as in the BSV model, BVSP and ISE are following NIKKEI respectively.

The results of ABSV model in Table $4 \mathrm{a}$ and $4 \mathrm{~b}$ shows that the highest and the lowest posterior means of beta parameter are again belong to ISE and S\&P as in the results of BSV and BSVF models. Posterior mean of phi persistency parameters are between the range of 0.959 and 0.9906 in all the stock returns, and displaying high persistency in conditional variance as in the previous models. Persistency parameter of HSI is considerably higher comparing to other developing market stock returns with the posterior mean of 0.9901. BVSP, IPC, ISE and MERV are following HSI respectively. In Table $4 \mathrm{~b}$ it is seen that the posterior means of persistency parameters for developed market stock returns are too close to each other and S\&P has the minimum posterior mean of persistency parameter with the value of 0.9887 . When examining the posterior means of persistency parameters on the basis of all markets generally, FTSE has the highest posterior mean and HSI, CAC, DAX, S\&P, BVSP, IPC, ISE and MERV are following FTSE respectively. Unit root in volatility do not exist in all the series. When examining the posterior means of $\rho$ leverage effect parameter, it is seen that developing market stock returns MERV, BVSP and HSI and developed market stock returns CAC and S\&P have negative values confirming the existence of leverage effect. FTSE has the maximum variability of volatility with the value of 1.4606, BVSP has the minimum variability with the value of 0.8572 .

The results of ABSVF model show that the highest and the lowest posterior means of beta parameter are belong to ISE and S\&P as in the previous models in Table $4 \mathrm{a}$ and $4 \mathrm{~b}$. Posterior mean of phi persistency parameters are between the range of 0.9635 and 0.9929 in all the stock returns, displaying high persistency in conditional variance as in the previous models. Persistency parameter of HSI is considerably higher comparing to other developing market stock returns as in the results of previous models with the posterior mean of 0.9929 in Table 4a. IPC, BVSP, ISE and MERV are following HSI respectively. In Table $4 \mathrm{~b}$ it is seen that the posterior means of persistency parameters for developed market stock returns are too close to each other and NIKKEI has the minimum posterior mean of persistency parameter with the value of 0.9843 . When examining the posterior means of persistency parameters on the basis of all markets generally, HSI has the highest posterior mean and FTSE, S\&P, CAC=DAX, , NIKKEI, IPC, BVSP, ISE and MERV are following HSI respectively. Unit root in volatility do not exist in all the 
series. When examining the posterior means of $\rho$ leverage effect parameter, it is seen that just developed market stock returns CAC and NIKKEI have negative values confirming the existence of leverage effect. FTSE has the maximum variability of volatility as in the previous models with the value of 1.4431. DAX, S\&P, HSI, MERV, IPC, CAC, ISE, BVSP, and NIKKEI are following FTSE. As in the previous models NIKKEI has the minimum variability, BVSP and ISE are following NIKKEI respectively.

The significance of all of the Bayesian models are examined by Geweke (1992) statistics (Z-scores). In the estimation results of BSV and ABSVF models, Geweke statistics of all parameters are between the range of +2 and 2 confirming the convergence is provided. Only the sigma parameter of CAC and the phi parameter of S\&P in the results of BSVF model, phi and sigma parameters of NIKKEI in the results of ABSV model have the values out of the range of $₫ 2$. Except these specified parameters convergency is provided for all models.

Heidelberger and Welch (1983) diagnostic test is used for detecting the stationarity of the Markov chain. All estimated parameters passed from the stationarity and halfwidth test, there is no need to run the chain longer or increase the number of iteration.

DIC criteria is used for comparing and choosing the most proper Bayesian model. DIC values for estimated models are in Table 5. When examining Table 5 BSV model has minimum DIC value for each stock return except S\&P. ABSV model is the best model for S\&P.

Table 5:- DIC values of BSV, BSVF, ABSV and ABSVF Models.

\begin{tabular}{|c|c|c|c|c|}
\hline & BSV & BSVF & ABSV & ABSVF \\
\hline MERV & 13721.3 & 13743.3 & 13733.8 & 13771.3 \\
\hline BVSP & 15897.5 & 15917.2 & 15914.2 & 15936.3 \\
\hline HSI & 13495.8 & 13497.2 & 13513 & 13517.4 \\
\hline IPC & 13600.9 & 13629.4 & 13604.4 & 13647.7 \\
\hline ISE & 17344 & 17412.4 & 17369.6 & 17405.2 \\
\hline FTSE & 10848.9 & 10873.2 & 10856.4 & 10880.8 \\
\hline CAC & 12785 & $12801.6^{*}$ & 12798.6 & 12819 \\
\hline DAX & 12933.9 & 12959.3 & 12935.2 & 12961.2 \\
\hline S\&P & 11039.9 & $11057.7^{*}$ & 11038.8 & 11072.1 \\
\hline NK & 13152.5 & 13167.3 & $13165.9^{*}$ & 13188.6 \\
\hline
\end{tabular}

* These models are left out of assessment because the results of Geweke statistics are not valid.

The models give better results for each stock return involving the classical SV are taking part in Table 6.

Table 6:- The Models That Give Better Results For Each Stock Return.

\begin{tabular}{|c|c|c|}
\hline MERV & BSV & \\
\hline BVSP & BSV & \\
\hline HSI & BSV & EGARCH $(1,1)-\mathrm{H}(3,0)$-SVM \\
\hline IPC & BSV & \\
\hline ISE & BSV & \\
\hline FTSE & BSV & EGARCH $(1,1)-\mathrm{H}(2,0)-$ SVM \\
\hline DAX & BSV & \\
\hline S\&P & BSV & \\
\hline NK & ABSV & \\
\hline
\end{tabular}

According to Table 6 it is seen that the results of classical SV models are significant for only IPC and DAX. Generally Bayesian models give the best results for each market stock returns.

\section{Conclusion:-}

The volatility modeling of developed and developing markets are aimed in this study. For this purpose classical stochastic volatility, Bayesian stochastic volatility, fat-tailed Bayesian stochastic volatility, asymmetric Bayesian 
stochastic volatility and Bayesian stochastic volatility model that allows both leverage effect and fat-tailed residuals are estimated and compared for 10 market stock returns to investigate which models give better results for developed and developing market stock returns. In the analysis MERVAL (MERV) (Argentina), BOVESPA (BVSP) (Brasil), HANGSENG (HSI) (China), IPC (Mexico), Istanbul stock exchange 100 (ISE 100) (Turkey) are taken as developing market daily stock returns and FTSE 100 (UK), CAC 40 (France), DAX (Germany), S\&P 500 (US), NIKKEI 225 (Japan) are taken as developed market daily stock returns.

The estimation results of classical stochastic volatility models by efficient method of moments are significant for only IPC and DAX. During the estimation of Bayesian stochastic volatility models, the most proper parameter values are found by trying different parameter values of priors which have been used in the important studies in the literature. At first Bayesian stochastic volatility models are estimated by simulation with 10000 iterations without specifying the initial values of the parameters, after that the posterior means of parameters are taken as initial values and then models reestimated with 1000000 iterations.

The variability of volatility is higher in upper quantiles according to lowers for each stock returns in all estimated Bayesian stochastic volatility models. While developed market return FTSE has the maximum variability of volatility in all models, again developed market return NIKKEI has the minimum variability in all models except asymmetric Bayesian stochastic volatility model. BVSP has the minimum variability for this model. The high variability represents high risk and high return values.

The results of the models show that Bayesian stochastic volatility models which have normal distributed residuals give the best results for all stock returns when comparing the deviance information criteria of the models except S\&P. Asymmetric Bayesian stochastic volatility model is the best model for S\&P. Because of determining different priors in accordance with data, the results of Bayesian stochastic volatility models are significant for all the stock returns. This represents superiority of Bayesian approach from other methods clearly.

\section{References:-}

1. Andersen, T., Bollerslev, T., Christoffersen, P., Diebold, F.: Volatility Forecasting, Penn Institute for Economic Research. Pier Working Paper 05-011, http://papers.ssrn.com/sol3/papers.cfm?abstract_id=673405 (2005). Accessed 10 July 2008

2. Andersen, T.:Stochastic Autoregressive Volatility: A Framework for Volatility Modeling, Mathematical Finance, 4, 75-102 (1994)

3. Black, F.:Studies of Stock Price Volatility Changes. In Proceedings of the 1976 Meetings of the Business and Economic Statistics Section, American Statistical Association, 177-181 (1976)

4. Black, F.,Scholes, M.: The Pricing of Options and Corporate Liabilities, Journal of Political Economy, 81, 637654 (1973)

5. Carlin, B.,Polson, N.G., Stoffer, D.: A Monte Carlo Approach to Non-normal and NonlinearState-Space Modelling, Journal of the American Statistical Association, 87, 493-500 (1992)

6. Carlin, B.P., Polson, N.G.: Inference for Non-conjugate Bayesian Models Using the Gibbs Sampler, Canadian Journal of Statistics, 19, 399-405 (1991)

7. Chib, S.,Nardari, F., Shephard, N.: Markov Chain Monte Carlo Methods For Stochastic Volatility Models, Journal of Econometrics, 108, 281-316 (2002)

8. Chib, S.,Greenberg, E. :Understanding the Metropolis-Hastings Algorithm, The American Statistician, 49, $327-$ 335 (1995)

9. Clark, P.K.: A Subordinated Stochastic Process Model with Finite Variance for Speculative Prices, Econometrica, 41, 135-156 (1973)

10. Duffie, D., Singleton, K.J.: Simulated Moments Estimation of Markov Models of Asset Prices, Econometrica, 61, 929-952 (1993)

11. Engle, R.:Autoregressive Conditional Heteroscedasticity with Estimates of the Variance of United Kingdom Inflation, Econometrica, 50, 4, 987-1007 (1982)

12. Gallant, A.R., and Long, J.R.: Estimating stochastic differential equations efficiently by minimum chi-square, Biometrika, 84, 125-141 (1997)

13. Gallant, A.R., Hsieh, D.A., Tauchen, G.E.: Estimation of stochastic volatility models with diagnostics, Journal of Econometrics, 8, 1, 159-192 (1997)

14. Gallant, A.R., Tauchen, G.E.: Which Moments to Match, Econometric Theory, 12, 657-681 (1996) 
15. Gallant, A.R., Nychka, D.W.: Semi-nonparametric maximum likelihood estimation, Econometrica, 55, 363-390 (1987)

16. Geweke, J.:Bayesian Comparison of Econometric Models, Working Paper 532, Research Department, Federal Reserve Bank of Minneapolis (1994b)

17. Geweke, J.:Comment On Bayesian Analysis Of Stochastic Volatility, Journal of Business and Economics Statistics, 12, 4, 371-417 (1994c)

18. Harvey, A. C., Shephard, N.: Estimation of an asymmetric stochastic volatility model for asset returns, Journal of Business \& Economic Statistics, 14, 4, 429 (1996)

19. Harvey, A.C., Ruiz, E., Shephard, N.: Multivariate Stochastic Volatility Models, Review of Economic Studies, 61, 247-264 (1994)

20. Heidelberger, P., and Welch, P.D.: Simulation Run Length Control in the Presence of an Initial Transient, Operations Research, 31, 1109-1144 (1983)

21. Heston, S.L.: A closed-form Solution for Options with Stochastic Volatility, with Application to Bond and Currency Options, Review of Financial Studies, 6, 2, 327-343 (1993)

22. Hull, J., and White, A.: The Pricing of Options and Assets with Stochastic Volatilities, The Journal of Finance, 42, 281-300 (1987)

23. Jacquier, E., Polson, N., Rossi, P.E.: Bayesian Analysis of Stochastic Volatility Models with Fat-Tails and Correlated Errors, Journal of Econometrics, 122, 185-212 (2004)

24. Jacquier, E., Polson, N., Rossi, P.E.: Stochastic Volatility: Univariate and Multivariate Extensions, Montreal: CIRANO, Scientific Series (1999)

25. Jacquier, E., Polson, N., Rossi, P.E.: Bayesian Analysis of Stochastic Volatility Models, Journal of Business and Economic Statistics, 12, 371-417 (1994)

26. Johnson, H., Shanno, D.: Option Pricing When the Variance is Changing, Journal of Financial Quantitative Analysis, 22, 143-152 (1987)

27. Kim, S., Shephard, N., Chib, S.: Stochastic volatility: Likelihood inference and comparison with ARCH models, Review of Economic Studies, 65, 361-393 (1998)

28. Mandelbrot, B.: The variation of Prices, Journal of Business, 36, 4, 394 (1963)

29. Melino, A., Turnbull, S.M.: Pricing Foreign Currency Options with Stochastic Volatility, Journal of Econometrics, 45, 239-265 (1990)

30. Meng, Y., Bayesian Analysis of a Stochastic Volatility Model, Department of Mathematics Uppsala University, Project Report (February 2009:1)

31. Meyer, R., Yu, J.: BUGS for a Bayesian analysis of stochastic volatility models, Econometrics Journal, 3, 198215 (2000)

32. Nelson, D.:Conditional Heteroscedasticity in Asset Returns: A New Approach, Econometrica, 59, 2, 347-370 (1991)

33. Rachev, S., Hsu, T.J., Bagasheva, B., Fabozzi, F.: Bayesian Methods in Finance, First Edition, John Wiley \& Sons, Canada (2008)

34. Raftery, A.E., Lewis, S.M.: One Long Run with Diagnostics: Implementation Strategies for Markov Chain Monte Carlo, Statistical Science, 7, 493-497 (1992)

35. Scott, L.O.: Option Pricing when the Variance Changes Randomly: Theory, Estimation and an Application, Journal of Financial and Quantitative Analysis, 22, 419-438 (1987)

36. Stein,E. M., Stein, J.C.: Stock Price Distributions with Stochastic Volatility: An Analytical Approach, Review of Financial Studies, 4, 727-752 (1991)

37. Taylor, S. J.: Modeling Financial Time Series, First Edition, John Wiley and Sons Chichester, UK (1986)

38. Van der Sluis, Pieter J.: Computationally attractive stability tests for the efficient method of moments, The Econometrics Journal, 1, 1, 203-227 (1998)

39. Wiggins, J.B.: Option Values under Stochastic Volatility: Theory and Empirical Estimates, Journal of Financial Economics, 19, 351-372 (1987)

40. Yu, J.: On Leverage in a Stochastic Volatility Model, Journal of Econometrics, Vol. 127, 165-178 (2005) 